RODRIGUES, M. G.S.; DA SILVA JÚNIOR, C. M.; AMORIM, D. C. G.; VERAS. M. L. e DOS ANJOS, D.S.C. O Jogo Lúdico Baralho Químico e Modelos Moleculares para o Ensino de Funções Orgânicas DOI: $10.31416 /$ rsdv. v8i1. 75

\title{
O Jogo Lúdico Baralho Químico e Modelos Moleculares para o Ensino de Funções Orgânicas
}

\section{The Playful Game Chemical Deck and Molecular Models for Teaching Organic Functions}

\author{
RODRIGUES, Maria das Graças Santos. Especialista em Ensino de Química e Biologia e \\ Licenciada em Química \\ Escola Estadual São José, Zona Rural. Rua A, Núcleo 02, S/N. Projeto de Irrigação Senador Nilo Coelho, Petrolina- \\ PE, CEP 56.330-130. Telefone: (87) 98827.4026 / E-mail: graci-nha-20@hotmail.com
}

DA SILVA JÚNIOR, Carlos Monteiro. Mestre em Ciências dos Materiais

Escola Estadual Manoel Messias Barbosa, Zona Rural. Agrovila Massangano, Petrolina-PE, CEP 56.302-900. Telefone: (87) 98812.2748 / E-mail: csjunior0@gmail.com

\begin{abstract}
AMORIM, Delza Cristina Guedes. Mestre em Educação, Cultura e Territórios Semiáridos IF SERTÃO-PE, Campus Petrolina. Rua Maria Luiza de Araújo Gomes Cabral, S/N. Jardim São Paulo, Petrolina-PE, CEP 56.316-686. Telefone: (87) 2101.4300 / E-mail: delza.cristina@ifsertao-pe.edu.br
\end{abstract}

VERAS, Maria Leopoldina. Doutora em Química Orgânica

IF SERTÃO-PE, Campus Petrolina. Rua Maria Luiza de Araújo Gomes Cabral, S/N. Jardim São Paulo, Petrolina-PE, CEP 56.316-686. Telefone: (87) 2101.4300 / E-mail: leopoldina.veras@ifsertao-pe.edu.br

DOS ANJOS, Débora Santos Carvalho. Doutora em Química Inorgânica

IF SERTÃO-PE, Campus Petrolina. Rua Maria Luiza de Araújo Gomes Cabral, S/N. Jardim São Paulo, Petrolina-PE, CEP 56.316-686. Telefone: (87) 2101.4300 / E-mail: debora.santos@ifsertao-pe.edu.br

\section{RESUMO}

Este projeto foi desenvolvido a partir da busca por estratégias diferenciadas que permitam ao aluno a construção do conhecimento de forma lúdica. Os objetivos deste trabalho consistiram na aplicação do Jogo Lúdico Baralho Químico e na construção de modelos moleculares para o ensino de funções orgânicas. Neste contexto, o despertamento do interesse pela ciência e o fortalecimento da interação entre discentes e docentes também são almejados. A pesquisa aqui descrita caracteriza-se como uma pesquisa-ação, de natureza quali-quantitativa. A intervenção didática foi realizada na Escola Estadual Jesuíno Antônio D’Ávila, Petrolina-PE. As seguintes etapas foram realizadas: (1) Levantamento dos conhecimentos prévios; (2) Discussão do tema funções orgânicas e construção dos Modelos Moleculares; (3) Elaboração do Jogo Lúdico Baralho Químico; (4) Aplicação do Jogo Lúdico Baralho Químico e (5) Avaliação da aprendizagem. Os modelos moleculares e o jogo lúdico foram de grande importância para o processo de ensino e aprendizagem, uma vez que percentagens de acertos entre 55 e $93 \%$ foram obtidas. Constatou-se também $100 \%$ de aceitação da metodologia utilizada. Um grande aproveitamento das atividades propostas foi então observado, o que vem reforçar a importância da busca e utilização de novas metodologias no ensino de química que venham a contribuir para o processo de ensino e aprendizagem. Além disto, foi possível uma forte interação entre os alunos, fundamentais para a construção do conhecimento.

Palavras-chave: química, modelos moleculares, jogos lúdicos.

\section{ABSTRACT}

This project was developed from the search for differentiated strategies that allow students to acquire knowledge in a playful way. This work aimed to apply the playful game Chemical Deck and construct molecular models to teach organic functions. It sparks interest in science and strengthens the interaction between students and teachers. The research described here is of a qualitative and quantitative nature. The didactic approach was carried out at the Jesuíno Antônio D'Ávila State School, Petrolina - PE. The following steps were taken: (1) Review of previous knowledge; (2) Discussion of the topic of organic functions and construction of Molecular Models; (3) Design and Development of the Playful Game Chemical Deck; (4) Application of the Playful Chemical Deck Game and (5) Evaluation of the learning experience. The molecular models and the playful game were of great importance for the teaching and learning process. The correct answers obtained were between 55 and $93 \%$. The methodology used by students was of an acceptance rate of $100 \%$. The proposed activities were very successful, reinforcing the importance of the search and use of new methodologies for the teaching of chemistry. In addition, strong student interaction was established, which is fundamental to the construction of knowledge.

Keywords: Chemistry, molecular models, playful games. 
RODRIGUES, M. G.S.; DA SILVA JÚNIOR, C. M.; AMORIM, D. C. G.; VERAS. M. L. e DOS ANJOS, D.S.C. O Jogo Lúdico Baralho Químico e Modelos Moleculares para o Ensino de Funções Orgânicas

\section{Introdução}

A busca por novas estratégias pedagógicas no ensino de química visa proporcionar uma prática educativa dinâmica e motivadora no espaço escolar. Neste contexto, se insere a utilização de atividades lúdicas com o objetivo de propiciar a integração e cooperação entre alunos e professores e alunos com seus pares, durante o processo de ensino e aprendizagem. Oliveira (2010) e Leite (2016) descrevem que o desinteresse dos alunos pelas Ciências ocorre, principalmente, devido ao processo de transmissão-recepção de conteúdo, sem estabelecer a devida correlação com a realidade e o contexto social em que os alunos estão inseridos. A utilização de dinâmicas lúdicas, o que inclui jogos, brinquedos e brincadeiras, favorece de forma complementar a aprendizagem, desde que os objetivos pedagógicos da atividade, estejam explicitados no planejamento (MACHADO et al, 2016).

Atualmente, é de suma importância as atividades lúdicas, pois são instrumentos que atraem, motivam, e estimulam o processo de construção do conhecimento, ou seja, a ludificação dos processos de ensino e aprendizagem da Química apresenta elevado potencial para desenvolver competências e habilidades cognitivas (Silva et al, 2017). É nesse cenário que o jogo didático ganhou espaço como instrumento motivador, despertando o interesse no processo de aprendizado do aluno, podendo ser definido, de acordo com Soares (2016), pelo equilíbrio existente entre duas funções, a função lúdica, aquela que propicia diversão e prazer, e a função educativa, relacionada ao uso dos jogos com a finalidade de ensinar. Ambas devem estar em equilíbrio, pois se a função recreativa predominar, não passará de um entretenimento e se a função educativa se evidenciar, será apenas um material didático. Seja qual for o contexto científico, tecnológico e social, o jogo didático pode ser também definido como uma atividade divertida, (PINHEIRO; SILVEIRA; BAZZO, 2009).

As atividades lúdicas podem contribuir como ferramentas de valor indispensável ao processo de ensino, favorecendo o interesse dos alunos por novos conhecimentos. Posto isto, é de competência do educador trabalhar metodologias diferenciadas em sala de aula, tornando desta forma, o ensino prazeroso e o aprendizado significativo para o aluno.

De acordo com Benedetti-Filho e Benedetti (2020), o desafio proporcionado pelos jogos catalisa uma maior assimilação dos assuntos trabalhados. Porto (2015) assegura que é fundamental que o professor tenha ou aprenda a ter uma "postura lúdica" no ambiente escolar, pois a existência dessa postura é capaz de fornecer inúmeros benefícios para a aprendizagem dos seus alunos, tais como favorecer a inteligência emocional, motivação, senso crítico, capacidade autoavaliativa, estímulo à criatividade, socialização e raciocínio lógico.

Diante desse cenário, acreditamos que as atividades lúdicas são estratégias pedagógicas importantes para a prática educacional contextualizada e interdisciplinar, capazes de potencializar a participação ativa dos alunos no espaço escolar. De acordo com Freire (1996), a escola deve proporcionar espaços para aulas dinâmicas que permitam o diálogo reflexivo entre estudantes e docentes. Por esses fatores, o jogo, como instrumento didático, têm sido cada vez mais valorizados nas escolas que se identificam com uma abordagem construtivista ou abordagens ativas e sociais.

Quando nos referimos ao ensino de química orgânica no ensino médio notamos que a prática comumente efetivada em sala de aula consiste na transmissão-recepção de conhecimentos que, 
RODRIGUES, M. G.S.; DA SILVA JÚNIOR, C. M.; AMORIM, D. C. G.; VERAS. M. L. e DOS ANJOS, D.S.C. O Jogo Lúdico Baralho Químico e Modelos Moleculares para o Ensino de Funções Orgânicas

muitas vezes, deixa lacunas no processo, fato este, mencionado por Zanon et. al (2008), que citam as dificuldades que permeiam o trabalho docente nesse nível de ensino e discutem sobre a opção de contribuir para o processo de ensino e aprendizagem através da dinâmica de jogos para o estudo das funções orgânicas.

Desta forma, ressalta-se que a espontaneidade com que os alunos participam do jogo, onde eles não têm que se preocupar com o erro, tal qual com a qualidade das respostas, e a facilidade na compreensão dos conteúdos de química caracterizam essa ferramenta como um apoio inovador e potencialmente eficaz no processo de ensino-aprendizagem (MATIAS et al., 2017).

Neste contexto, o projeto "O Jogo Lúdico Baralho Químico e Modelos Moleculares para o Ensino de Química" foi motivado pela constatação da dificuldade dos alunos em aprender química pelo uso apenas do método de exposição oral. Portanto, considerou-se a utilização de metodologias lúdicas para o ensino do conteúdo de química orgânica, buscando envolver o discente com o tema discutido em sala de aula e facilitar o processo de ensino-aprendizagem. Sendo assim, surgiram as ideias da adaptação do jogo de cartas tradicional para um baralho químico e da utilização de modelos moleculares na construção de cadeias moleculares para o ensino das funções orgânicas.

\section{Metodologia}

Este projeto caracteriza-se como uma pesquisa-ação, de natureza quali-quantitativa. A intervenção didática foi baseada na elaboração e aplicação do Jogo Lúdico Baralho Químico e na construção de Modelos Moleculares como facilitadores do processo de ensino e aprendizagem do conteúdo de funções orgânicas. Foi realizada na Escola Estadual Jesuíno Antônio D’Ávila - EJAD, localizada em uma área periférica no Submédio São Francisco, Petrolina - PE, em uma turma do $3^{\circ}$ ano, com 40 (quarenta) alunos. A duração do projeto foi de 3 (três) semanas, perfazendo um total de 6 (seis) aulas.

A aplicação deste projeto deu-se nas seguintes etapas: (1) Levantamento dos conhecimentos prévios; (2) Discussão do tema funções orgânicas e construção dos Modelos Moleculares; (3) Elaboração do Jogo Lúdico Baralho Químico; (4) Aplicação do Jogo Lúdico Baralho Químico e (5) Avaliação da aprendizagem.

\section{Levantamento dos conhecimentos prévios}

Anteriormente a aplicação do Jogo Lúdico Baralho Químico e da construção dos Modelos Moleculares, foi aplicado um pré-teste individual contendo 5 (cinco) questões sobre a química orgânica extraídas do livro didático de química Sardella (2005). Nesta etapa, avaliou-se os conhecimentos prévios dos alunos sobre o conteúdo funções orgânicas.

\section{Discussão do tema funções orgânicas e construção dos modelos moleculares}

Nesta etapa, o tema funções orgânicas foi abordado na sala de aula com o objetivo de introduzir o assunto apresentando conceitos básicos. Neste sentido, os alunos do $3^{\circ}$ ano do ensino médio, com o auxílio da professora de química e dos licenciandos (PIBID), montaram estruturas 


\section{Revista Semiárido De Visu}

RODRIGUES, M. G.S.; DA SILVA JÚNIOR, C. M.; AMORIM, D. C. G.; VERAS. M. L. e DOS ANJOS, D.S.C.

O Jogo Lúdico Baralho Químico e Modelos Moleculares para o Ensino de Funções Orgânicas

moleculares utilizando os modelos moleculares, discutindo e exemplificando a classificação e nomenclatura dos compostos orgânicos.

\section{Elaboração do Jogo Lúdico Baralho Químico}

Durante as observações da sala de aula foi perceptível o desinteresse que os alunos do grupo em questão tinham com a disciplina, considerando-a de difícil compreensão. Desta forma, realizouse uma pesquisa no portal de Química Nova na Escola (QNEsc) - Sociedade Brasileira de Química (SBQ), utilizando-se as palavras chave: química, modelos moleculares, jogos lúdicos, na busca de estratégias pedagógicas que dinamizassem as aulas.

Logo após a busca no portal, foram selecionados alguns artigos científicos e decidiu-se pelo jogo de naipes, por ser uma estratégia de baixo custo e facilmente adaptável ao tema a ser trabalhado em sala de aula - funções orgânicas. Essa metodologia foi escolhida por perceber que o jogo é uma ferramenta diferenciada e que possibilitaria a construção do conhecimento, motivando o aluno a trabalhar em grupo de forma dinamizada e participativa, buscando não apenas a compreensão do conteúdo, mas também a interação entre aluno-professor e aluno-aluno.

Importante ressaltar que na dinâmica de elaboração do jogo, utilizaram-se duas formas, sendo uma mais elaborada, por meio do uso de softwares e impressão das cartas na gráfica, e outra mais simples, utilizando materiais de baixo custo, como papel-ofício, tesoura e hidrocor, permitindo desta forma que o aluno desenvolva e revele sua criatividade na elaboração das cartas (Quadro 1).

Quadro 1: Materiais utilizados para elaboração das cartas do Jogo Lúdico Baralho Químico.

\begin{tabular}{|c|c|}
\hline Material impresso na gráfica & Material elaborado pelo aluno \\
\hline $\begin{array}{l}\text { 1. Programa Chemsketch; } \\
\text { 2. Programa Microsoft Office } 2013 \text { - } \\
\text { Publisher; } \\
\text { 3. Papel Couchê (Dimensão } 8 \mathrm{~cm} \times 11 \mathrm{~cm} \\
\text { da carta); } \\
\text { 4. Livros para pesquisa sobre funções } \\
\text { orgânicas. }\end{array}$ & $\begin{array}{l}\text { 1- Folha de ofício (A4); } \\
\text { 2- Tesoura; } \\
\text { 3- Régua; } \\
\text { 4- Caneta, lápis de cor ou hidrocor; } \\
\text { 5- Livros para pesquisa sobre funções } \\
\text { orgânicas. }\end{array}$ \\
\hline
\end{tabular}

Fonte: Próprios autores.

\section{Aplicação do Jogo}

Em seguida, o jogo lúdico foi trabalhado contando com a participação de 29 (vinte e nove) alunos. Os estudantes foram divididos em 6 (seis) grupos, e em seguida foi explanado de forma detalhada as regras do jogo. Cada grupo foi monitorado por um líder, que acompanhava a aplicação dessa metodologia e mediava o processo de aprendizagem dos alunos. A aplicação do jogo durou aproximadamente 1 hora e 30 minutos.

\section{Avaliação da aprendizagem}




\section{Revista Semiárido De Visu}

RODRIGUES, M. G.S.; DA SILVA JÚNIOR, C. M.; AMORIM, D. C. G.; VERAS. M. L. e DOS ANJOS, D.S.C. O Jogo Lúdico Baralho Químico e Modelos Moleculares para o Ensino de Funções Orgânicas

A avaliação da aprendizagem foi realizada através da aplicação de um pós-teste contendo 5 (cinco) perguntas referentes ao conteúdo funções orgânicas. Além disto, introduziu-se 5 (cinco) perguntas referentes à metodologia aplicada, visando avaliar a sua aceitação.

\section{Resultados e Discussão}

Inicialmente aplicou-se um pré-teste com o objetivo de realizar um levantamento dos conhecimentos prévios dos alunos sobre o conteúdo de funções orgânicas. 0 pré-teste continha 5 (cinco) questões. Os resultados obtidos mostraram que uma grande parte dos alunos se equivocou nas questões ou não sabia responder, conforme gráfico 1 .

Gráfico 1: Percentagens (\%) de erros, acertos e sem respostas obtidas no Pré-teste.

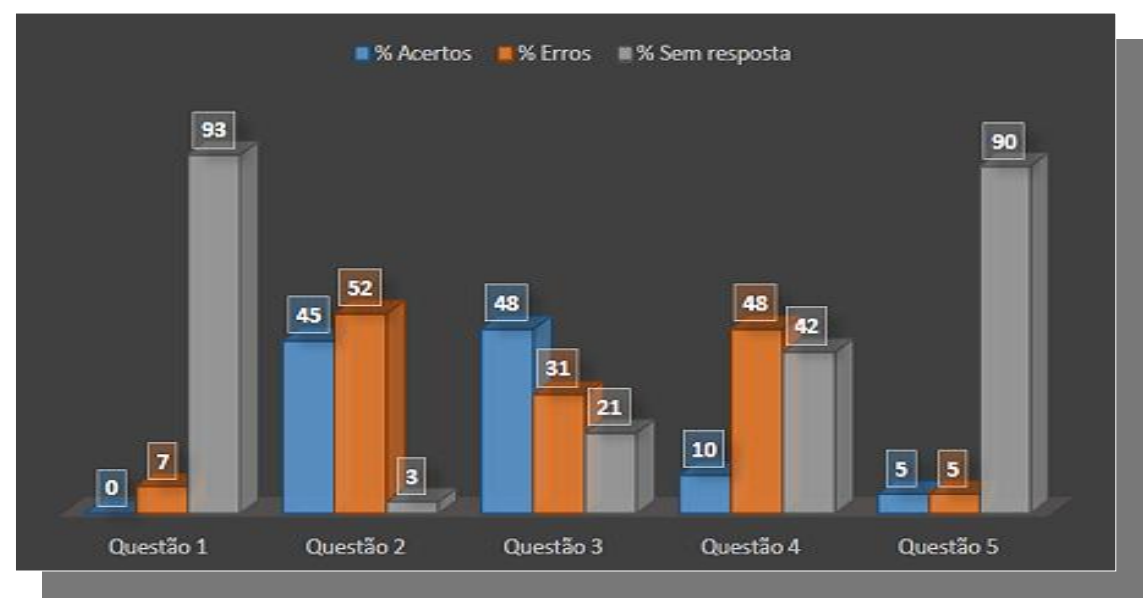

Fonte: Próprios autores.

O gráfico 1 apresenta os percentuais de erros, acertos e sem respostas das questões descritas no pré-teste. A primeira questão envolve a nomenclatura oficial dos ácidos carboxílicos, de acordo com a União Internacional da Química Pura e Aplicada (IUPAC). Percebeu-se que a maioria dos alunos desconhecia o tema. A segunda e terceira questões abordavam os números de carbonos insaturados em uma cadeia carbônica e os tipos de fórmulas moleculares. Observou-se que houve uma percentagem de acertos de $45 \%$, demonstrando que os estudantes possuíam algum conhecimento prévio. Contudo, quanto as questões quatro e cinco, que traziam questionamentos acerca dos tipos de funções orgânicas e suas nomenclaturas, constatou-se uma baixa percentagem de acertos, sendo $10 \%$ e $5 \%$, respectivamente.

Os resultados obtidos nesse pré-teste serviram como impulso motivador para que os licenciandos buscassem metodologias diferenciadas para abordar o conteúdo funções orgânicas, que trouxessem interatividade e que despertassem maior interesse pelo componente curricular, mostrando a importância do estudo dessa ciência, de forma lúdica.

De acordo com a análise feita por Crespo (2011), em artigos publicados pelas revistas editadas pela Sociedade Brasileira de Química (SBQ), as atividades lúdicas quando elaboradas e aplicadas, promovem com eficiência a construção do conhecimento. Após a aplicação e análise do pré-teste, 


\section{Revista Semiárido De Visu}

RODRIGUES, M. G.S.; DA SILVA JÚNIOR, C. M.; AMORIM, D. C. G.; VERAS. M. L. e DOS ANJOS, D.S.C.

O Jogo Lúdico Baralho Químico e Modelos Moleculares para o Ensino de Funções Orgânicas

deu-se a abordagem e discussão do tema funções orgânicas de forma interativa e mediada, assim como a construção de moléculas orgânicas a partir dos modelos moleculares (Figura 1). Houve, portanto, a apresentação de diferentes moléculas orgânicas, com as montagens das estruturas, discutindo-se as classificações e nomenclaturas dos compostos orgânicos.

Figura 1: Discussão do tema funções orgânicas e construção das moléculas a partir dos modelos moleculares.
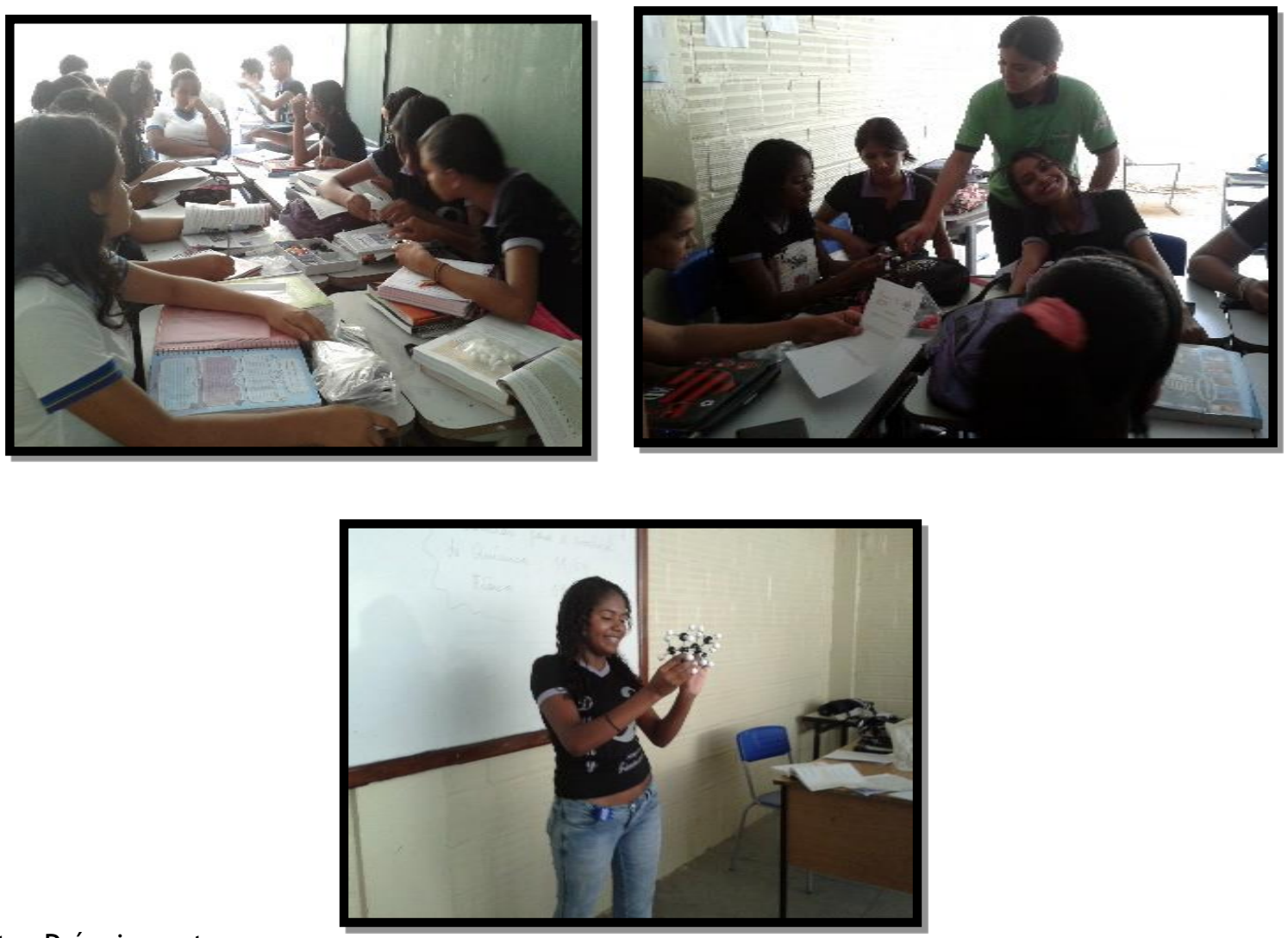

Fonte: Próprios autores.

A utilização dos modelos moleculares foi de grande importância para o processo de ensino e aprendizagem, pois permitiu interação entre os alunos, fundamentais para a construção do conhecimento. Os alunos demostraram interesse no envolvimento para a montagem das cadeias carbônicas, observando com curiosidade e atenção os modelos. Santana et al (2009) consideram o lúdico uma metodologia de ensino capaz de estabelecer ações integradas e articuladas que visam uma aprendizagem crítica e reflexiva. Os modelos moleculares mostram de forma visível como os átomos estão ligados, assim formando cada tipo de cadeia carbônica.

Em seguida, o Jogo Lúdico foi concebido e elaborado a partir das observações realizadas em sala de aula, conforme descrito na metodologia. Na Figura 2 são apresentadas as imagens das cartas do baralho químico, sendo: a) frente das cartas, b) carta especial coringa e c) quatro tipos de cartas diferentes. 
RODRIGUES, M. G.S.; DA SILVA JÚNIOR, C. M.; AMORIM, D. C. G.; VERAS. M. L. e DOS ANJOS, D.S.C.

O Jogo Lúdico Baralho Químico e Modelos Moleculares para o Ensino de Funções Orgânicas

Figura 2: a) Frente das cartas do Baralho Químico $(8 \mathrm{~cm} \times 11 \mathrm{~cm})$, b) Carta Especial Coringa e c) Quatro tipos de cartas diferentes.

a)

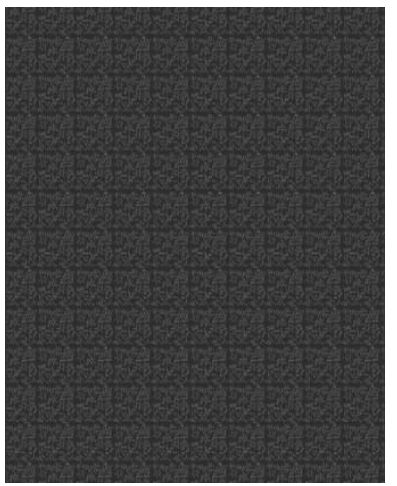

b)

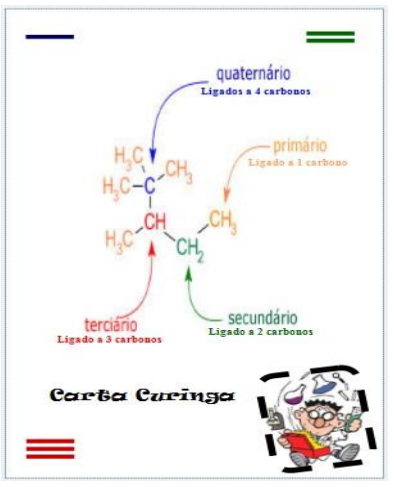

C)

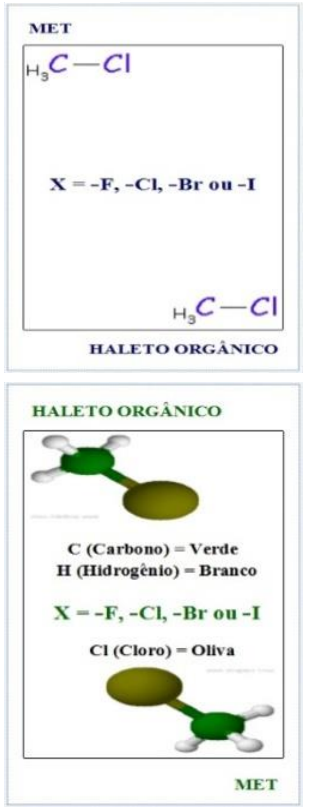

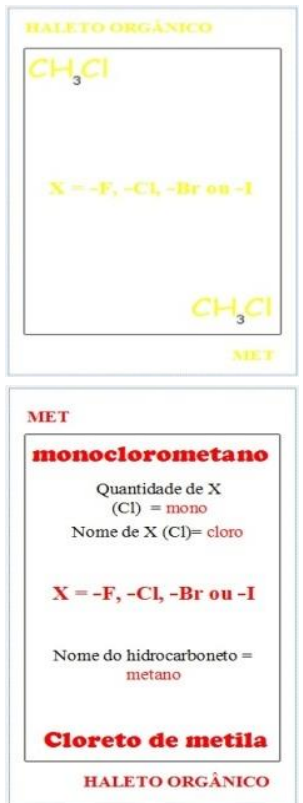

Fonte: Próprios autores.

O Jogo Lúdico Baralho Químico é composto por 61 (sessenta e um) naipes, onde 5 (cinco) destes são cartas coringas com diferentes informações. São 4 (quatro) tipos de cartas sobre funções orgânicas, a saber: Carta Molécula na cor verde (Figura 3); Carta Fórmula na cor amarela (Figura 4); Carta Estrutura na cor azul (Figura 5); Carta Nomenclatura na cor vermelha (Figura 6); 5 (cinco) cartas coringas de informações diferentes (Figura 7). Para cada grupo funcional (álcool, aldeído, cetona, ácido carboxílico, éter, éteres, amina, amidas, etc.) foram confeccionadas uma carta molecular, uma carta fórmula, uma carta estrutura e uma carta nomenclatura.

Figura 3: Carta Molécula.

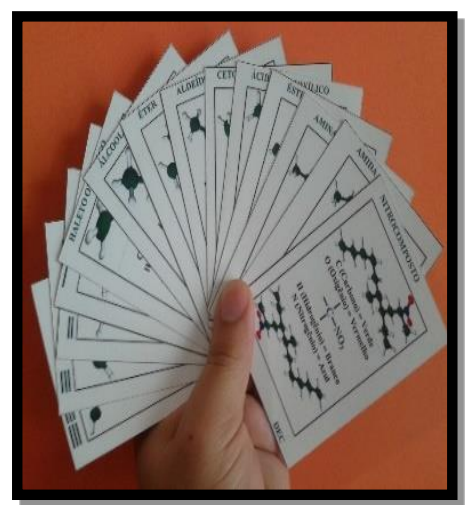

Fonte: Próprios autores.
Figura 4: Carta Fórmula.

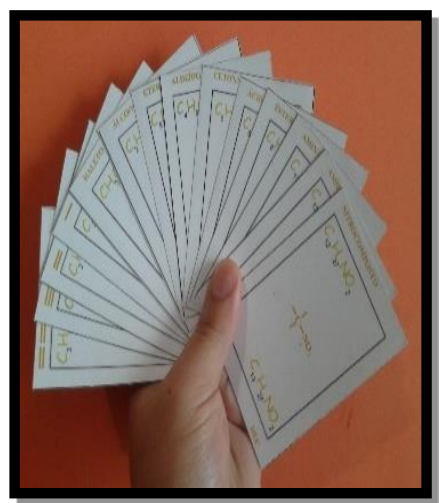

Fonte: Próprios autores.
Figura 5: Carta Estrutura.

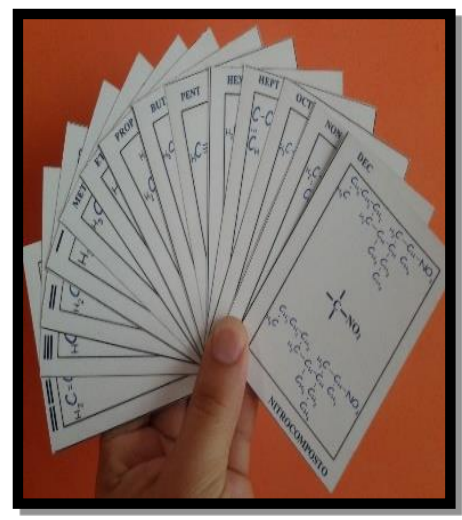

Fonte: Próprios autores. 


\section{Revista Semiárido De Visu}

RODRIGUES, M. G.S.; DA SILVA JÚNIOR, C. M.; AMORIM, D. C. G.; VERAS. M. L. e DOS ANJOS, D.S.C. O Jogo Lúdico Baralho Químico e Modelos Moleculares para o Ensino de Funções Orgânicas

Figura 6: Carta Nomenclatura.

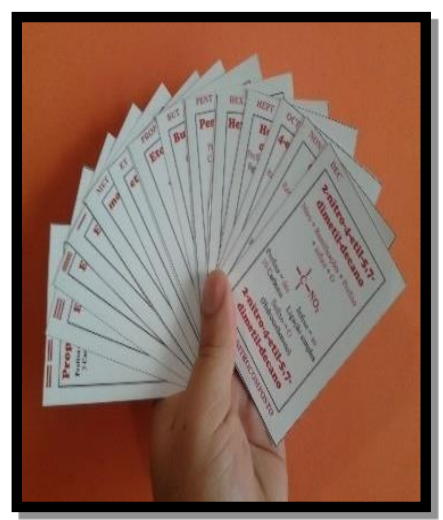

Fonte: Próprios autores.
Figura 7: Carta Coringa.

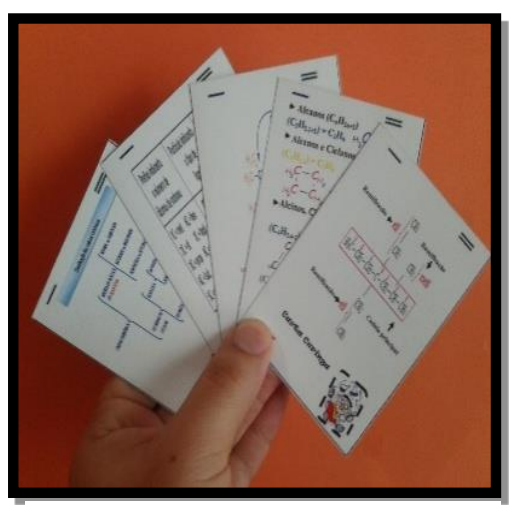

Fonte: Próprios autores.

Deve-se utilizar 1 (um) baralho para 2 (dois) jogadores ou utilizar 2 (dois) baralhos para 4 (quatro) jogadores. Cada baralho possui 5 (cinco) cartas coringas. No caso de usar mais de um baralho, deixar apenas 5 (cinco) cartas coringas com informações diferentes.

Inicialmente um dos jogadores deve distribuir 9 (nove) cartas para cada jogador. As cartas restantes devem formar um monte que será utilizado para saque, geralmente esse monte fica no centro para facilitar o acesso dos jogadores.

Os jogadores decidem quem iniciará o jogo ou formulam alguma maneira de selecionar o iniciante. Este jogador iniciante deve sacar uma carta do monte de saque, analisar a carta considerando as 9 (nove) cartas que já possui. Após análise, pode não a considerar útil e simplesmente descartá-la, ou no caso dessa carta ser útil, deverá permanecer com ela e descartar uma das 9 (nove) que possui que não seja do seu interesse.

Após este momento, o próximo jogador decide se aquela carta descartada é útil. Em caso afirmativo, ficará de posse da carta e descartará uma da 9 (nove) que possui, ou se não é útil poderá sacar uma carta do monte de saque. No caso de sacar, o jogador analisará a carta, se ela não for útil, a descartará, caso contrário, permanece com a carta e descarta uma das 9 (nove) que não the seja útil.

Desta forma, esses passos serão repetidos sistematicamente entre os jogadores e, portanto, será formado no centro, um monte de descarte. Contudo, o jogador só poderá escolher pegar uma carta desse monte, se ela estiver no topo e as demais cartas somente poderão ser pegas caso o monte de saque acabe. Neste caso, o monte de descarte é embaralhado e torna-se um monte de saque novamente. 0 vencedor é aquele jogador que formar os 3 (três) primeiros trios de cartas.

Com 9 (nove) cartas em mãos, o jogador deve formar 3 (três) trios para vencer. Os trios podem ser formados de 2 (duas) formas: trios consecutivos ou iguais. Os trios consecutivos consistem em agrupar 3 (três) cartas de um mesmo naipe, as possibilidades de formarem mais de um trio consecutivos iguais dependem de quantos baralhos são utilizados no jogo, em ordem consecutiva, como por exemplo: Carta Estrutura do mesmo naipe Met, Et, Prop. A ordem dos prefixos indicativos 


\section{Revista Semiárido De Visu}

RODRIGUES, M. G.S.; DA SILVA JÚNIOR, C. M.; AMORIM, D. C. G.; VERAS. M. L. e DOS ANJOS, D.S.C.

O Jogo Lúdico Baralho Químico e Modelos Moleculares para o Ensino de Funções Orgânicas

do número de átomos de carbono em uma molécula é: Met, Et, Prop, But, Pent, Hex, Hept, Oct, Non, Dec, como apresentado na Figura 8.

Figura 8: Ordem das cartas.

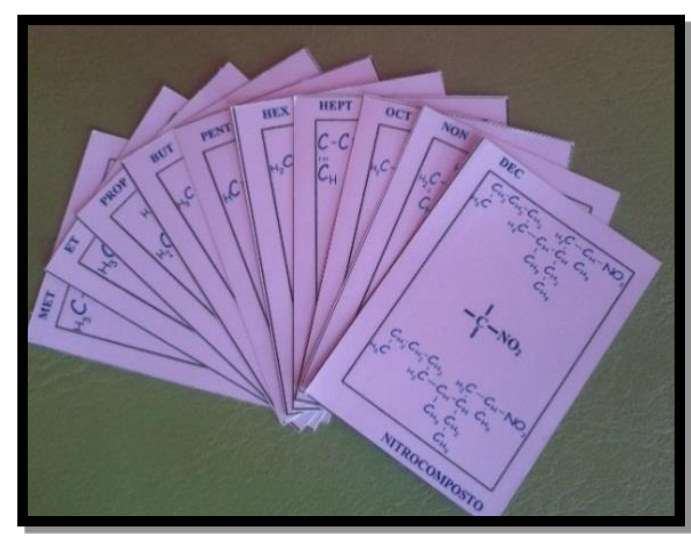

Fonte: Próprios autores.

As cartas Propadieno e Butadiino podem ser substituídas pelas cartas Eteno ou Etino, sendo a substituição podendo ser feita para formar um trio com ligação simples, ligação dupla e ligação tripla como é mostrado na Figura 9.

Figura 9: Carta Propadieno, Butadiino e Etino.

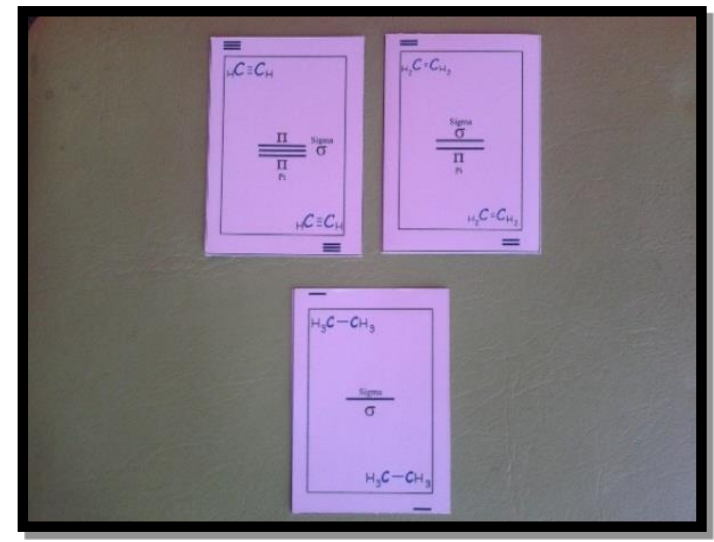

Fonte: Próprios autores.

É o obrigatório que as cartas sejam do mesmo naipe para a formação dos trios. Trios como: Carta Molécula $=$ Met, Carta Estrutura $=\mathrm{Et}$, Carta Nomenclatura $=$ Prop não são válidos como trio (Figura 10). 
RODRIGUES, M. G.S.; DA SILVA JÚNIOR, C. M.; AMORIM, D. C. G.; VERAS. M. L. e DOS ANJOS, D.S.C. O Jogo Lúdico Baralho Químico e Modelos Moleculares para o Ensino de Funções Orgânicas

Figura 10: Grupo com naipes errados.

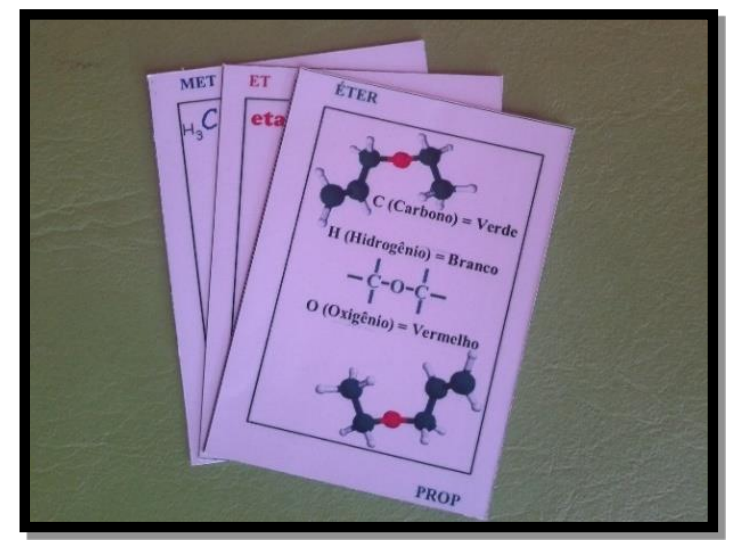

Fonte: Próprios autores.

Os trios iguais são os trios formados pelo agrupamento de 3 (três) cartas de mesmo valor como mostra a Figura 11. Exemplo: Carta Fórmula $=$ Amida, Carta Nomenclatura $=$ Amida, Carta Molécula $=$ Amida, não podendo ser repetidas.

Figura 11: Trio igual correto.

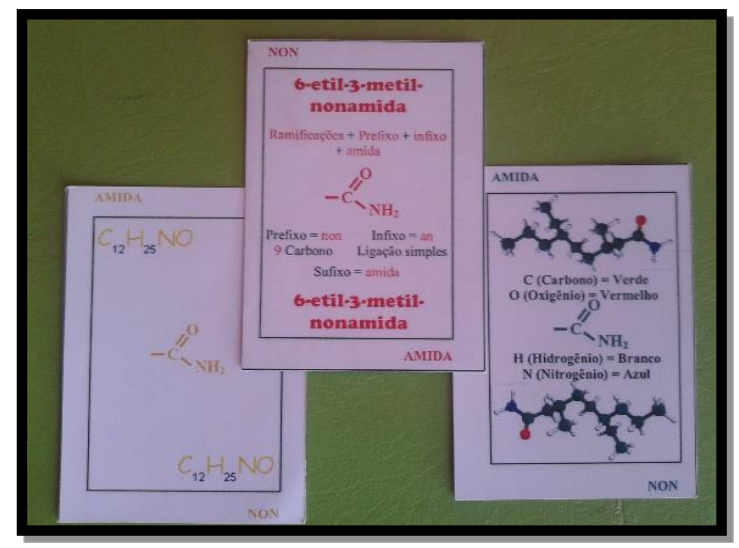

Fonte: Próprios autores.

Em seguida, o Jogo Lúdico Baralho Químico foi aplicado em sala de aula. A Figura 12 apresenta imagens do momento da aplicação do jogo.

Figura 12: Momento da aplicação do Jogo Lúdico Baralho Químico em sala de aula. 
RODRIGUES, M. G.S.; DA SILVA JÚNIOR, C. M.; AMORIM, D. C. G.; VERAS. M. L. e DOS ANJOS, D.S.C.

O Jogo Lúdico Baralho Químico e Modelos Moleculares para o Ensino de Funções Orgânicas
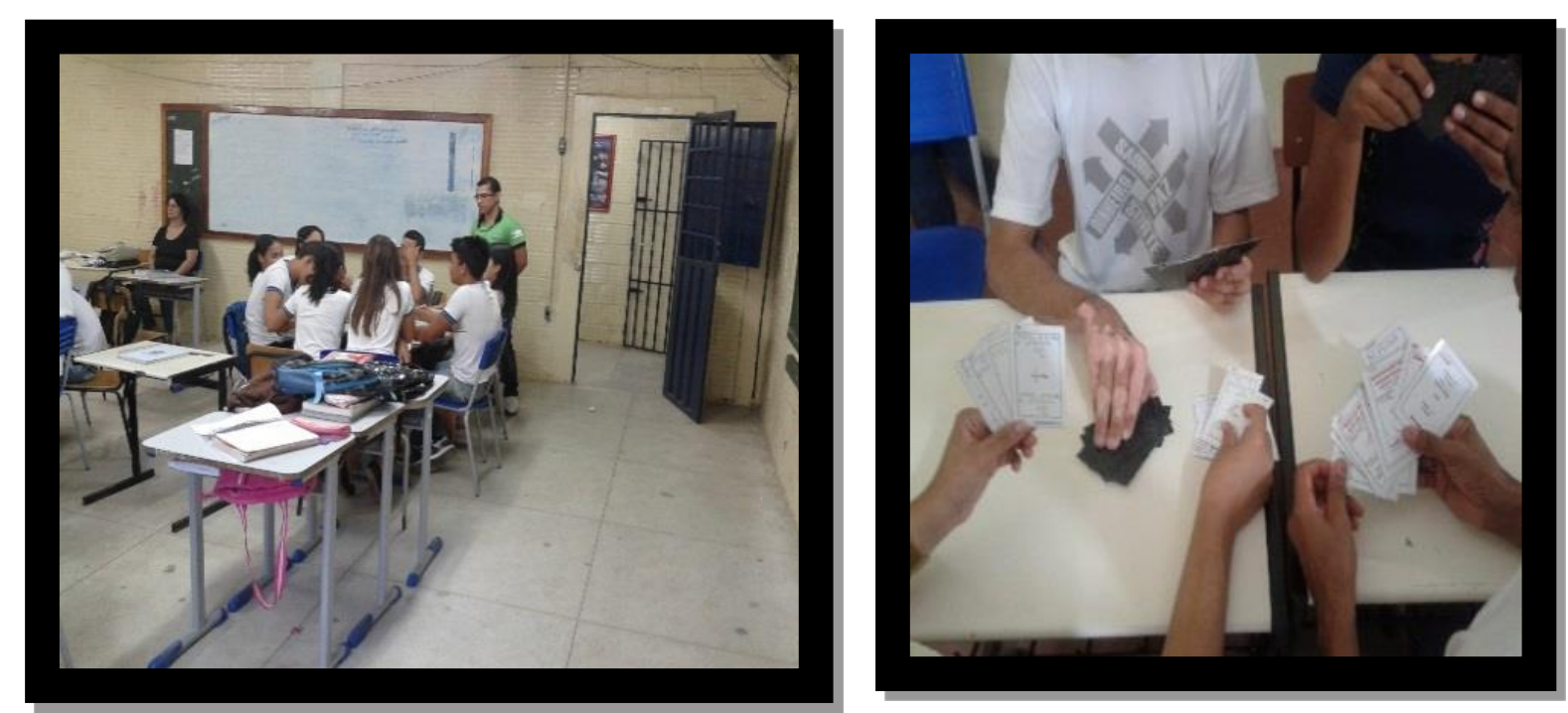

Fonte: Próprios autores.

Após a aplicação do jogo, foi realizada outra atividade individual (pós-teste), que consistia em 5 (cinco) perguntas referentes ao conteúdo funções orgânicas e 5 (cinco) perguntas referentes à metodologia aplicada em sala de aula. Observou-se um grande avanço na construção do conhecimento posteriormente a aplicação do jogo proposto, conforme o gráfico 2 .

Gráfico 2: Percentagens (\%) de erros, acertos e sem respostas obtidas no Pós-teste.

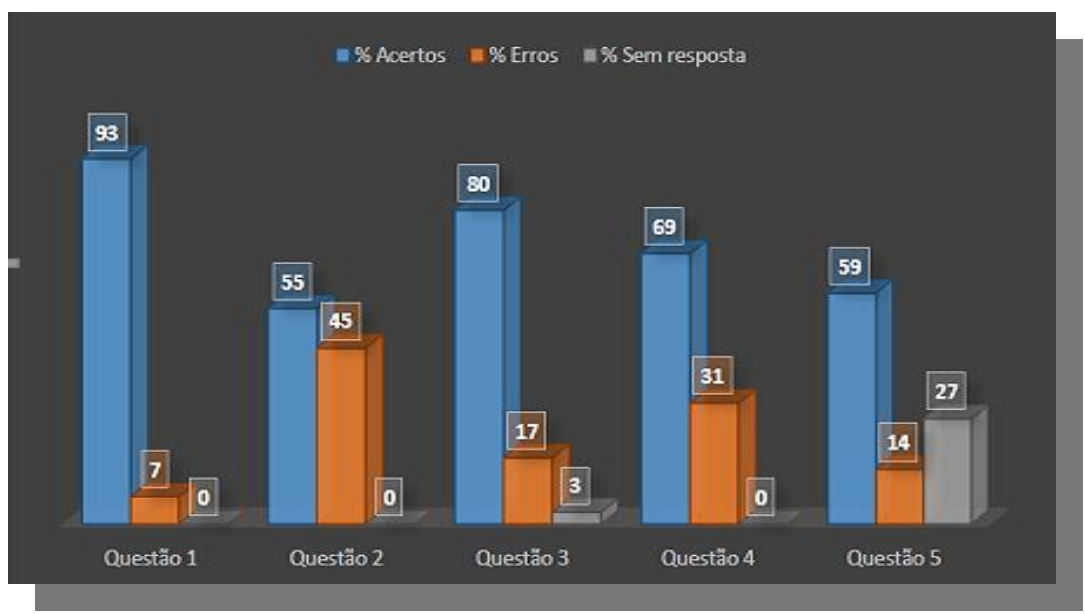

Fonte: Próprios autores.

De acordo com o gráfico 2 é possível perceber avanços consideráveis nas percentagens de acertos em todas as questões comparadas às percentagens obtidas no pré-teste, obtendo-se resultados na faixa de $55-93 \%$ de acertos. Esses avanços estão relacionados diretamente a utilização de novas metodologias em sala de aula, como as atividades lúdicas aqui aplicadas. Segundo Carvalho et al (2013), uma possibilidade de diferenciação pedagógica é a utilização de recursos metodológicos que favoreçam a ludicidade, interatividade e a ligação dos conteúdos com aspectos cotidianos da vida dos alunos, como a brincadeira. 


\section{Revista Semiárido De Visu}

RODRIGUES, M. G.S.; DA SILVA JÚNIOR, C. M.; AMORIM, D. C. G.; VERAS. M. L. e DOS ANJOS, D.S.C. O Jogo Lúdico Baralho Químico e Modelos Moleculares para o Ensino de Funções Orgânicas

Diversos resultados positivos têm sido obtidos com a utilização de jogos no ensino de química ou ciências com diferentes enfoques e aplicações. Conforme observado pela pesquisa desenvolvida por Oliveira et al (2018), o jogo educativo aplicado ao conteúdo de química, demonstra ser uma ferramenta que pode vir a ser um recurso didático facilitador do ensino e da aprendizagem nesta disciplina e que também pode servir para mobilizar e melhorar a relação aluno-professor.

Em relação a metodologia aplicada nesta pesquisa, questionou-se aos alunos opiniões sobre a forma de aplicação, viabilidade e a importância das ferramentas diferenciadas em sala de aula, e nesse sentido constatou-se que houve $100 \%$ de aceitação da metodologia utilizada. Como relata Cunha (2000), o jogo educativo contribui para o estreitamento da relação aluno-professor e aluno-aluno, podendo facilitar o processo de inclusão, o que corrobora com os resultados obtidos neste estudo.

\section{Conclusões}

Um grande aproveitamento das atividades propostas foi então observado, o que vem reforçar a importância da busca e utilização de novas metodologias no ensino de química que venham a contribuir para o processo de ensino e aprendizagem. Além disto, foi possível uma forte interação entre os alunos, fundamentais para a construção do conhecimento.

Ressalta-se ainda que o jogo lúdico foi determinante no processo de aprendizagem dos alunos sobre o conteúdo de funções orgânicas, devido ao grande número de acertos às perguntas realizadas, assim como houve grande aceitação da metodologia aplicada.

Os licenciando ao apresentar o conteúdo com recursos lúdicos, oportunizaram aos alunos a aprenderem não apenas o conhecimento de funções orgânicas, mas também a interagirem de modo efetivo em suas relações cotidianas de sala de aula, envolvendo todos os personagens do processo (professores e alunos), uma vez que o conhecimento é construído a partir da interação, discussão e convívio.

\section{Agradecimentos}

Ao PIBID - CAPES; Ao IF SERTÃO-PE; A SEDUC-PE.

\section{Bibliografia}

BENEDETTI, E. e BENEDETTI, L. P. S. Um Jogo Didático para Revisão de Conceitos Químicos e Normas de Segurança em Laboratórios de Química. Química Nova na Escola, v. 42, n. 1, p. 37-44, FEVEREIRO, 2020.

CARVALHO, C. M., CABRAL, J. R. R., CORREA FILHO, J. A. e CASTRO, A. M. B. O lúdico no ensino de física: a brincadeira e a simulação computacional como recursos no ensino-aprendizagem. In: XX Simpósio Nacional de Ensino de Física - SNEF 2013, São Paulo: UFSJ. v.1, p. 1 - 7, 2013.

CRESPO, L. C. e GIACOMINI, R. As atividades lúdicas no ensino de química: uma revisão da revista Química Nova na Escola e das reuniões anuais da Sociedade Brasileira de Química. Universidade 


\section{Revista Semiárido De Visu}

RODRIGUES, M. G.S.; DA SILVA JÚNIOR, C. M.; AMORIM, D. C. G.; VERAS. M. L. e DOS ANJOS, D.S.C. O Jogo Lúdico Baralho Químico e Modelos Moleculares para o Ensino de Funções Orgânicas

Estadual do Norte Fluminense Darcy Ribeiro/ Centro de Ciência e Tecnologia - Laboratório de Ciências Químicas, 2011.

CUNHA, M.B. Jogos didáticos de Química. Santa Maria: Grafos, 2000.

FREIRE, P. Pedagogia da autonomia: saberes necessários à prática educativa. São Paulo: Paz e Terra, 1996.

LEITE, L. M. Digerindo a química biologicamente: a ressignificação de conteúdos a partir de um jogo. Química Nova na Escola, v. 38, n. 1, p. 12-19, 2016.

MACHADO, P. S., RIBEIRO, J. H. C., SILVA, T. P.; TABER M. e PASIN, E. B. Atividades lúdicas relacionadas a questões hídricas: inclusão de abordagens CTS no currículo de Biologia do Ensino Médio. Cadernos da Educação Básica, v.1, p. 55-66, 2016.

MATIAS, F. S., NASCIMENTO, F. T. e SALES, L. L. M. Jogos lúdicos como ferramenta no ensino de química: teoria versus prática. Revista de Pesquisa Interdisciplinar, Cajazeiras, n. 2, suplementar, p. 452-464, set. de 2017.

PINHEIRO, N. A. M., SILVEIRA, R. M. C. F. e BAZZO, W. A. O contexto científico-tecnológico e social acerca de uma abordagem crítico-reflexiva: perspectiva e enfoque. Revista lberoamericana de Educación, 49(1), 1-14, 2009.

OLIVERIA, A. L., OLIVEIRA, J.C.P., NASSER, M.J.S. e CAVALCANTE, M.P. O Jogo Educativo como Recurso Interdisciplinar no Ensino de Química. Química Nova Na Escola, v. 40, n. 2, p. 89-96, 2018.

OLIVEIRA, R. J. O ensino das ciências e a ética na escola: interfaces possíveis. Química Nova na Escola, v. 32, n. 4, p. 227-232, 2010.

PORTO, M. G. C. Jogo, TIC e ensino de química: uma proposta pedagógica. Recife: UFRPE, 2015. 249 f. Tese - Programa de Pós-Graduação em Ensino das Ciências, Universidade Federal Rural de Pernambuco, Recife, 2015.

SANTANA, E. M. e BRITO, D. R. Atividades lúdicas como elementos mediadores da aprendizagem no ensino de ciências da natureza. Enseñanza de las Ciencias. Número extra. VIII Congresso Internacional sobre Investigación en La Didáctica de las Ciencias, Barcelona, pp. 1007-1011, 2009.

SARDELLA, O. Química: ensino médio. São Paulo: Ática, v.1, 2005.

SILVA, A. C. R., SILVA, P. L. L. e CLEOPHAS, M. G. Jogar e compreender a Química: ressignificando um jogo tradicional em didático. Revista de Educação em Ciências e Matemática, v.13, n. 28, p. 132150, Jul-Dez 2017.

SOARES, M. H. F. B. Jogos e Atividades Lúdicas no Ensino de Química: Uma Discussão Teórica Necessária para Novos Avanços. Revista Debate em Ensino de Química, v.2, n.2. p. 5 -13, 2016.

ZANON, D. A. V.; GEUERREIRO, M. A. S.; OLIVEIRA, R. de. Jogo didático ludo químico para o ensino de nomenclaturas dos compostos orgânicos: projeto, produção, aplicação e avaliação. Ciências \& Cognição, V. 13, n. 1, p. 72-81, 2008. 